\title{
A Educação encontra a Arte: Apontamentos Político-Pedagógicos sobre Direitos e Pequena Infância ${ }^{4}$
}

\begin{abstract}
Resumo: Para problematizar a tendência de impor nas pré-escolas, e muitas vezes nas creches, uma pedagogia pautada na lógica escolar, fundada nas ciências da regularidade, voltada ao ensino analítico, centrada na docência e na transmissão de conhecimentos, propomos uma interlocução entre arte, educação e pequeníssima infância. O encontro entre arte e infância favorece a discussão em torno das lacunas na formação do pedagogo(a) que convive com crianças pequenas, principalmente com as pequenininhas, para educá-las muito além do cognitivismo reinante. A partir de filósofos e pensadores interessados na vida e seus transbordamentos, abordamos a imaginação poética, a alegria e a complexidade de aprender, o direito à beleza e à experiência linguageira que emerge do corpo sensível, para reivindicar a emergência políitica de uma outra Pedagogia da infância. A experiência do corpo sensível e linguageiro, em suas primeiras aprendizagens, evoca uma pedagogia que não separa experiência e saber, corpo e mente, pensamento e ação no mundo. Essa inseparabilidade permite tanto resistir às bases exclusivamente científicas da Pedagogia e seu tecnicismo estrutural - a didática, quanto afirmar a relevância da arte na formação docente em sua potência de aglutinar encontros poéticos, políticos e pedagógicos que garantam o direito pleno à infância e à educação.
\end{abstract}

Palavras-chave: Arte. Pedagogia. Direitos. Pequena infância.

\section{Education meets Art: Political-Pedagogical notes on Rights and Early Childhood Education}

Abstract: In order to problematize the tendency of imposing in preschools (and very often in day care centers) a pedagogy based on the school logic, rooted in the sciences of regularity, focused on the analytical teaching, centered on the teacher and knowledge transmission, we propose an interlocution between art, education and the very earliest childhood. The encounter between art and childhood fosters the discussion about the gaps in the teacher's formation, who is always among young children, mainly the tiny young ones, to educate them way beyond their prevailing cognitivism. From philosophers and thinkers interested in life and its unfoldings, we approach the poetic imagination, the joy and the complexity of learning, the right to beauty and the language experience that emerges from the sensitive body to raise the political urgency for another Childhood Pedagogy. The experience of the sensitive and linguistical body in its first learning summons a pedagogy which does not segregate experience from knowledge, body from mind, thought from action in the world. This inseparability allows one not only to resist the exclusively scientific bases of Pedagogy and its structural technicality - the didactics - but also to assess the relevancy of art in the teaching formation and its power to agglutinate poetic, political and pedagogical meetings that guarantee full rights to childhood and education.

Keywords: Art. Pedagogy. Rights. Early Childhood.

\footnotetext{
1 Doutora em Educação pela Universidade Federal do Rio Grande do Sul. Professora do Departamento de Educação da Universidade de Santa Cruz do Sul - UNISC.

2 Doutora em Educação pela Universidade Estadual de Campinas. Professora colaboradora no Departamento de Pedagogia da Faculdade de Educação da Universidade do Estado de Santa Catarina - FAED/UDESC.

3 Doutora em Educação pela Universidade de São Paulo. Professora da Faculdade de Educação da Universidade Estadual de Campinas - UNICAMP.

${ }^{4}$ Este texto, com algumas modificações, originalmente foi publicado em inglês no livro organizado pelo Professor da Universidade de Hanoover Wolfgang Schneider intitulado "Theatre for Early Years - Research in Performing Arts for Children from Birth to Three", pela editora alemã Peter Lang, em 2009.
} 


\section{Carta dos direitos da criança à arte e à cultura}

\section{As crianças têm o direito...}

1. de se aproximar da arte em todas as suas vertentes: teatro, música, dança, literatura, poesia, cinema, artes visuais e multimídia;

2. de experimentar as linguagens artísticas, pois elas são saberes fundamentais;

3. de fazer parte dos processos artísticos que nutrem a inteligência emotiva de cada uma, e que ajuda a desenvolver a sensibilidade e a competência artística de uma forma harmônica;

4. de desenvolver, através da relação com as artes, a inteligência corporal, semântica e icônica;

5. de desfrutar dos produtos artísticos de qualidade, criados para todas as crianças, mesmo no que diz respeito à diferentes faixas etárias;

6. de ter uma relação com a arte e com a cultura sem serem tratados como consumistas, mas como sujeitos competentes e, além de tudo, sensíveis;

7. de frequentar às instituições artísticas e culturais disponíveis na cidade, seja com a família ou com a escola, para descobrir e viver tudo o que o território oferece;

8. de participar dos eventos artísticos e culturais com frequência, e não apenas ocasionalmente, durante a vida escolar e a vida nas creches e pré-escolas;

9. de conviver com a família o prazer de uma experiência artística;

10. de ter um sistema integrado entre a escola e as instituições artísticas e culturais, pois só uma interação continua pode oferecer uma cultura viva;

11. de frequentar e visitar museus, teatros, bibliotecas, cinemas e outros lugares de cultura e espetáculo, juntos com as colegas da escola;

12. de viver experiências artísticas acompanhadas dos professores, enquanto mediadores necessários para sustentar e valorizar as percepções de todos;

13. a uma cultura laica, no que diz respeito das diferenças de identidade;

14. à integração, se imigrantes, através do conhecimento e do convívio do patrimônio artístico e cultural da comunidade na qual vivem;

15. a projetos artísticos e culturais, levando em consideração as diferentes habilidades;

16. a lugares idealizados e estruturados para serem acolhidos em diversas idades;

17. de atender a uma escola que seja o verdadeiro caminho de acesso para uma cultura ampla e pública;

18. de participar das propostas artísticas e culturais da cidade, independentemente das condições sociais e econômicas a que pertence, porque todas as Crianças têm direito à arte e à cultura.

(La Baracca, Teatro Testoni Ragazzi, Bologna, 2011)

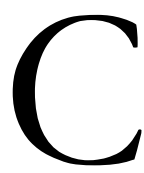

om a enorme mudança em curso na contemporaneidade na maneira de ver e entender as crianças, também produto das atuais modificações sociais na organização do tempo cotidiano, das transformações na família e do papel da mulher, discutiremos aqui a emergência de uma pedagogia que contempla a pequeníssima infância como sujeito de direitos e, portanto, com direito a ser educada por profissionais diplomados, no coletivo infantil das creches, complementar à esfera privada da família, resgatando a arte já presente na paidea grega (ciência, arte e técnica). 
Neste texto, escrito por três mulheres professoras e pesquisadoras de crianças de 0-3 anos, empenhamo-nos em criar uma interlocução entre arte, educação e pequeníssima infância superando também as nossas lacunas da formação pedagógica.

Nosso encontro busca problematizar o mito da imaginação livre e desenfreada na infância, o mito da arte como adereço da pedagogia, assim como o mito da ciência neutra que sempre vai garantir o direito das crianças à educação e o seu reconhecimento como cidadã mesmo sem estar atenta

que pode vir a ser uma maneira de captura e de escolarização precoce no sentido da disciplinarização, normalização do corpo, das palavras e gestos, na produção de um determinado tipo de aprendiz trazendo, portanto, uma rejeição à alteridade e às diferenças que as crianças anunciam, enquanto tais (ABRAMOWICZ, 2003, p.16).

\section{Dimensão poética das primeiras aprendizagens}

Quando uma criança chega ao mundo, algo lança-se no movimento insaciável do aprender: invenção e existência aderem-se, o imprevisível acontece, faz-se, forma-se, torna-se. Por estar desarmada de conceitos e ideias do que sejam as coisas mundanas, a criança estabelece uma relação direta com o que a cerca. Seu olhar torna-se um olhar primal, poético, seduzido pela admiração, encantado pela novidade. A imaginação torna-se louca vontade de ver e integrar o detalhe ordinário que, por desafiar o familiar, exige o movimento de tornar-se operador fabuloso de sentidos. O ficcional emerge, então, como amplificação do ato de decifrar e interpretar o mundo para torná-lo inteligível. Por isso, para Bachelard, o poeta é aquele que preservou em si a maneira direta da criança. Em cada poeta há uma infância preservada na linguagem. Na criança, o poético emerge como ato de aprender a interrogar e valorar o vivido para ficcioná-lo; como modo gradativo - multitemporal - do corpo complexificar experiências linguageiras de pertencimento e participação no mundo.

Infância e arte, solidárias em seus respectivos movimentos de abertura à vida, ao imprevisível e à novidade que é iniciar um movimento no mundo, interrogam a pedagogia em seu generalizado desencanto pelo poder poético do corpo produzir, extrair, inventar, multiplicar sentidos e imantar o mundo de significados.

O desencanto com a mundanidade e com a dimensão da vida compartilhada emerge da crença pedagógica de ser necessário primeiro ensinar a ouvir e olhar para depois aprender a sentir e "ter ideias espontâneas". A seriedade e o tédio simplificam a ação de tornar inteligível o vivido e fazem a educação na infância confluir como momento de aprender a estancá-lo até uma realidade imóvel e imutável: um realismo absurdo ao turbilhão da vida que reduz o real à palavra que nomeia e explica o mundo. A pedagogia esquece que, desde o nascimento, o corpo já está irremediavelmente comprometido com a complexidade de aprender a extrair e formular sentidos, pois é exigido a imaginar e correr os riscos de expor-se e significar-se na convivência mundana. O importante a reter, aqui, é o poder poético da imaginação mobilizar o corpo e favorecer a constituição de um pensamento complexificando-se na alternância entre real e ficcional. 
A interlocução entre as fenomenologias da imaginação criadora em Gaston Bachelard, do corpo em Maurice Merleau-Ponty e da ação em Paul Ricoeur, permite afirmar que a imaginação não é dinâmica desordenada, vestígio fantasmal da percepção visual, mas dinâmica projetiva que encontra toda sua força transfigurativa ao colocar o corpo em linguagens e engendrar narrativas que plasmam ações na convivência mundana. Nesta perspectiva, a imaginação não se encerra na mente mas é ato alimentado pelo corpo operante no instante de tomar a iniciativa de agir enquanto modo gradativo do corpo aprender a realizar a cópula ${ }^{5}$ entre imaginação e razão, entre o sensual e o mental (RICHTER, 2005).

As fenomenologias do corpo, da imagem e da ação apontam para a importância formativa da experiência de encantamento das primeiras aprendizagens extraídas de um saber fazer - fingere $e^{6}$ que $^{-}$ desde a infância constitui a linha de demarcação a partir da qual aprendemos a interpretar e engendrar ações que dão às coisas outro curso. Trata-se de negar a redutora cisão entre o "eu penso" (mente) e o "eu posso" (corpo) para destacar a educação infantil como tempo e lugar de aprender a encantar-se com o poder de operar linguagens, como espaço formativo de temporalização do corpo infantil que aprende a complexificar-se no e com o mundo através das diferentes formas de recontar e refazer o vivido com outros. Aprender, então, não implica apenas explorar, mas reconfigurar a realidade, conseguir refazer os próprios passos, poder recontar algo que queremos compartilhar.

Para Ricoeur (1986, p.14), o caráter comum da experiência humana emerge da sua qualidade temporal. Assim como tudo que contamos e recontamos toma tempo e chega no tempo, tudo que se desenvolve no tempo pode ser recontado. A narrativa nos marca, nos articula, nos faz compreender e tomar posse da temporalidade desde os primeiros aprendizados desencadeados pelos relatos ficcionais. A importância das primeiras aprendizagens está na emergência do complexo processo de aprender a desvendar os segredos das linguagens ao arranjar e rearranjar o real pela intensidade narrativa de um corpo encenando o mundo.

Todo pensamento que desencadeia uma transfiguração da realidade, ao animar as coisas e emprestar-lhes uma existência poética, é transformativo do pensamento e dos acontecimentos mundanos: na simultaneidade que engendra pensamentos, inventa realidades. O poético emerge justamente na audácia ou na astúcia de um pensamento que não se satisfaz representando - ou re-produzindo - o mundo, antes regojiza-se ao improvisar outros mundos ao tomar a iniciativa de agir ao elaborar coordenações entre ações que produzem efeitos no real pelo poder poético de abertura à outras dimensões de realidade. Aqui, o compromisso inadiável da pedagogia favorecer aprendizagens que recuperem para a racionalidade o poder produtivo da imaginação poética.

Tanto a arte quanto a infância apontam para o início radical de algo que dá outro curso às coisas: um gesto, uma marca, uma incisão no mundo já interpretado que, ao agir como se não houvesse um sentido assinalado, inventa-o na emergência do espanto e da admiração diante do ainda não sentido, não visto e não nomeado. Portanto, não se trata de discorrer sobre arte $e$ infância, mas entre elas firmar

${ }^{5}$ O termo cópula é aqui utilizado para afirmar a inseparabilidade entre o sentido relacional e o sentido existencial contido no ato de instaurar, transformar e transfigurar imagens através do corpo operante no mundo.

${ }^{6}$ Ficção etimologicamente tem origem no termo latino fingo que significa figurar, formatar, modelar o barro com as mãos. Ficção é fingere e fingere é fazer. Fingir não é propor engodos ou mentir, mas elaborar estruturas inteligíveis (RICHTER, 2005). 
uma cumplicidade de mútuos aprendizados. Com elas re-aprender o pacto poético de fazer nascimentos: com elas recuperar o delírio dos começos na humana aventura de afrontar o desconhecido e o incerto.

Alcançar as repercussões das primeiras aprendizagens do corpo no mundo exige um retorno filosófico ao domínio do vivido, do pré-reflexivo, do imediato: o corpo sensível operante enquanto elo que nos lança na experiência imprevisível e compartilhada de nossa história encarnada num único mundo.

Para Bachelard (1989, p.9), "é na carne, nos órgãos, que nascem as imagens primordiais. Essas primeiras imagens materiais são dinâmicas, ativas; estão ligadas a vontades simples, espantosamente rudimentares" que fazem começar algo, tomar a iniciativa de ir até as próprias coisas, sair de si para entrar no mundo e nele inscrever pensamentos e ações que promovem elos de pertencimento e participação.

Nesse movimento sensível que o torna simultâneo às coisas e aos outros, há sempre algo diante dele: a experiência de decifrar. Não temos outro modo de saber do mundo senão afirmando sua indeterminação a cada instante que se torna em nós. Como já disse Deleuze (1998, p.10), "não há aprendiz que não seja 'o egiptólogo' de alguma coisa”, que não enfrente enigmas sem os decifrar, pois são os problemas que dão sentido às soluções e não o contrário. Nessa perspectiva, aprender é uma tarefa infinita já que não há nada prefigurado, previsto, predeterminado a aprender.

Aqui, a ação de aprender não é síntese, menos ainda processo cumulativo do percebido, mas metamorfose do corpo em abertura para a experiência temporal de tornar-se na simultaneidade que o mundo vai tornando-se para si e para os outros. Metamorfose que extrai uma aprendizagem ao forjar pensamento na abertura de começar algo para alcançar o limite do visível e aumentar o campo de visibilidade.

Tal abertura supõe aprender a ter visões, ou seja, aprender a operar a visão silenciosa para abrir um campo nomeável e dizível em linguagens que engendram um processo histórico particular ao emergir como temporalização corporalizada ${ }^{7}$. O tempo acontece no corpo e o modifica. É só por isso, para Agamben (2005), que temos infância: porque não nascemos já falantes e temos que aprender a instalar no corpo uma história linguageira. In-fan é aquele que não tem voz, que não nasce falando; aquele que está aprendendo a falar e a ser falado, a ver e a ser visto. É apenas nessa condição que a história não pode ser o progresso continuo da humanidade falante ao longo de um tempo linear: ela é intervalo, descontinuidade, irrupção do pensamento, do porvir, pois temos que aprender a estar em linguagens, temos que aprender os fazeres do corpo que significam a existência coletiva. Cada vez pela primeira vez.

Em Agamben (2005), a carência de linguagem é a condição de sua emergência e, assim, o percurso de sua aprendizagem é o mesmo para todas as crianças: todas têm que aprender a falar (e a projetar visões) com outros. Liberada do condicionamento subjetivo que define a origem como um ponto em uma cronologia, como causa inicial cindindo um tempo antes e um tempo depois, "a origem de um tal 'ente' não pode ser historicizada, porque é ela mesma historicizante; é ela mesma a fundar a possibilidade de que exista algo como uma "história"' (AGAMBEN, 2005, p. 61). O humano é histórico justamente por não vir ao mundo já falante e ter que engendrar a fala e o ser falado desde a imersão em uma história. Por não estar inscrito na

7 O enfoque enactivo de Francisco Varela (VARELA, THOMPSON, ROSCH, 1997), inspirado em Merleau-Ponty, afirma a cognição como ação corporizada na qual o corpo é concebido simultaneamente como estrutura física e como estrutura vivida e experiencial, isto é, tanto biológico como fenomenológico. 
língua desde sempre, o discurso não the vem dado "por natureza". Por não falar desde "sempre" e ter que aprender a colocar-se em fala - a falar-se - a infância não é natural, universal e nem pode ser antecipada.

Agamben (2005) destaca a infância como condição da história a partir da diferença entre língua e discurso, entre semiótica e semântica, na qual o humano não pode entrar na língua como sistema de signos sem a transformar radicalmente em semântica, sem a constituir em discurso. Essa transformação radical, que afirma a infância como dimensão original do humano, como poder do humano aprender a falar e ser falado, implica negar uma visão politicamente dominante baseada no eixo cronológico e no discurso racionalista de um processo psicológico progressivo que coloca a criança no pólo zero. Tal visão permite dividi-la em diferentes faixas - que variam segundo as teorias - em direção ao fim da vida. Esse ponto situado como zero torna legítimo não apenas engendrar fases e desenvolvimentos sustentados no plano do déficit em relação ao plano lógico-matemático adulto como autorizar a "especialização" de áreas do conhecimento e teorias para "administrar" tais faixas etárias.

Arendt (2004) contesta essa trajetória temporal cronológica afirmando que a única resistência à fatalidade de uma vida limitada pelo nascimento e pela morte é a ação - o agir - capaz de interromper o curso inexorável e automático da vida cotidiana em direção à morte porque pode interrompê-lo e iniciar algo novo: "perene advertência de que os homens, embora devam morrer, não nascem para morrer, mas para começar" (ARENDT, 2004, p.258).

A ação - o falar e o agir - nos libera, enquanto regularidade do infinitamente improvável (ARENDT, 2004), da condenação do ciclo incessante do processo vital e de suas leis inexoráveis por se exercer diretamente entre humanos na convivência mundana. O desejo de estar com outros, na ação e no discurso ${ }^{8}$, permite iniciar processos novos e intermináveis que fazem da pluralidade a condição da ação humana ${ }^{9}$. Esta capacidade de iniciar algo, com toda a surpresa e imprevisibilidade que é inerente a tudo que começa, tem raízes na natalidade: só o recém-chegado, o nascido, possui a capacidade de iniciar algo, isto é, de iniciativa. Para Arendt (2004, p.259), é o nascimento de novos seres humanos, o novo começo a ação de que são capazes em virtude de terem nascido - que pode conferir fé e esperança no mundo. A promessa está no rompimento da continuidade. Cada criança que chega ao mundo, o mantém e o altera, faz parte e é estrangeira. Cada criança que nasce introduz a descontinuidade na narração do tempo humano: todo começo - ou irrupção da existência é delirante.

É o que Valéry (1999, p.203) reafirma ao destacar que a criança, quando nasce, traz consigo diversas possibilidades. Após alguns meses aprende a falar e a andar, aprende dois tipos de ação que lhe permitirão recorrer, em circunstâncias acidentais, para extrair o que puder em resposta às suas necessidades ou às suas imaginações. Ao aprender a caminhar, descobrirá que pode não só andar, mas também correr; e não só andar e correr, mas também dançar. É um grande acontecimento. Ela inventou e descobriu ao mesmo tempo uma

8 Para Arendt (2004, p.191), "se a ação, como início, corresponde ao fato do nascimento, se é a efetivação da condição humana da natalidade, o discurso corresponde ao fato da distinção e é a efetivação da condição humana da pluralidade, isto é, do viver como ser distinto e singular entre iguais".

9 Convém destacar que em Arendt (2004, p.19), "as condições da existência humana - a própria vida, a natalidade e a mortalidade, a mundanidade, a pluralidade e o planeta Terra - jamais podem 'explicar' o que somos, pela simples razão de que jamais nos condicionam de modo absoluto". 
espécie de utilidade de segunda ordem para seus membros, uma generalização de sua fórmula de movimento. Efetivamente, enquanto o andar é, em suma, uma atividade bastante monótona e pouco perfectível, essa nova forma de ação, a dança, permite uma infinidade de criações e de variações ou configurações.

As crianças abordam o mundo e o desconhecido de modo diferente dos adultos: em sua inexperiência - outra temporalidade - o abordam encantadas, admiradas, espantadas, investigativas. Tal abordagem acontece no âmbito dos saberes sensíveis que emergem das raízes corporais: um saber primal, fundante, direto, anterior aos processos de raciocínio e reflexão, que exige o encontro com as qualidades do mundo. Sons, cores, sabores, texturas e odores nos colocam no mundo e são por nós corporalizados. Por provocar um excesso sensivel, uma relação direta, é preciso compartilhar a experiência. Compartilhar é estar junto em um tempo, é compartilhar um ritmo determinado, seus intervalos, suas ressonâncias e repercussões.

Afirmar, com Merleau-Ponty (1999, p.23), que uma criança pode agir e perceber antes de pensar, que pode começar a colocar seus sonhos nas coisas, seus pensamentos nos outros, e com eles formar um bloco comum de existência, na qual as perspectivas de cada um ainda não se distinguem porque misturadas no encontro dos corpos, não pode ser ignorada pela pedagogia em nome da tentativa de elucidação analítica da experiência. Não interessa aqui saber como elucidar os dilemas, mas destacar como há abertura para o pensamento sem que a ocultação do mundo seja excluída (MERLEAU-PONTY, 1999).

Para sublinhar que nem todas as condutas estão no mesmo plano, Francastel (1993, p.12) destaca a observação de Valéry sobre a distinção do primeiro passo sobre todos os demais que o seguem. Para o poeta, a "primeira vez" não implica apenas prolongar gestos anteriormente preparados, mas fundamentalmente introduzir uma irreversibilidade nas condutas da criança. Walter Benjamin (1995, p.105), em Rua de mão única, contribui para abarcarmos o irrepetível que é aprender algo que nos redimensiona quando afirma: "posso sonhar como no passado aprendi a andar. Mas isso de nada adianta. Hoje sei andar; porém, nunca mais poderei tornar a aprendê-lo".

O tempo da corporalidade ${ }^{10}$ infantil é o lugar de intensas aprendizagens. É aqui, e não em outra idade, que a criança vai aprendendo a movimentar-se, caminhar, pegar e mexer nas coisas, gostar e desgostar, chorar, rir, correr, pular, cair, ter medo e se maravilhar. Aprendizagens fundantes de um corpo que culturalmente também vai aprendendo a olhar, falar, cantar, ouvir, desenhar, modelar, dançar, pintar, contar, fazer-de-conta. Vai aprendendo, rápida ou lentamente, a complexidade do agir e emocionar-se na convivência com outros, aprendendo a interpretar e tomar decisões, a imaginar e narrar, a relacionar e valorar. Aprende a tornar-se o que é e o que pode vir a ser no fluir da convivência com outros, ao viver intensamente momentos privilegiados de aprendizagens - porque momento de extrema plasticidade único em seu acontecer: o momento da primeira vez!

$\mathrm{O}$ acontecer pela primeira vez distingue-se das demais condutas porque não pode tornar a ser aprendida! A primeira vez é insubstituível em seu acontecimento corporal único e singular pela intensidade

10 Para Merleau-Ponty (1999), como para Francisco Varela (VARELA, THOMPSON, ROSCH, 1997), o termo corporalidade tem duplo sentido: abarca o corpo como estrutura experiencial vivida e o corpo como o contexto ou âmbito dos processos cognitivos. É afirmar o corpo como dimensão simultaneamente biológica e fenomenológica. 
da expectativa, da novidade, do inusitado que é fazer emergir a ruptura com o já corporizado, atualizandoo. O corpo sempre é reservatório.

As primeiras aprendizagens são irreversíveis, só podem ser repetidas. Repetição, aqui, não no senso comum do fazer igual, mas enquanto realimentação que implica a contínua reelaboração do que aconteceu antes. Experiências não apenas imediatamente agradáveis, mas realimentadoras de outras por vir. Para a filosofia da diferença, "a repetição só é uma conduta necessária e fundada apenas em relação ao que não pode ser substituído” (DELEUZE,1988, p.22). Nessa perspectiva, não se trata de mero acréscimo de uma segunda e uma terceira vez à primeira, mas de "elevar a primeira vez à enésima 'potência'. Sob esta relação da potência, a repetição se reverte, interiorizando-se”(DELEUZE, 1988, p. 22).

Se há algo que toda criança faz, quotidianamente, é recorrer à repetição de movimentos, gestos, sons, palavras. Repetição que, talvez, nas palavras de Deleuze (1988, p. 22), seja "o eco de uma vibração mais secreta, de uma repetição interior e mais profunda no singular que a anima". Reiteração que surge no fluir do encontro dos corpos e que, por não ser redundante em suas novidades, revigora e impregna a história de um corpo se constituindo na repetição de gestos que já estavam lá na primeira vez.

Estar envolvido implica estar tomado pelo acontecimento. Só aprendemos quando estamos por inteiro naquilo que fazemos. E comprometer-se envolve também padecimentos e frustrações. Portanto, convém advertir que não supõe abordar o envolvimento como motivação psicológica para a aprendizagem, isto é, não aprendemos apenas o que nos dá prazer ou porque nos é prazeroso. Deleuze (1998, p.46), compreende que a decepção - ela mesma plural e variável - é componente fundamental da busca ou do aprendizado, pois toda aprendizagem é uma interpretação de signos ou de hieróglifos. Implica compreender que "nos tornamos marceneiros somente nos fazendo sensíveis aos signos da madeira, ou médicos, sensíveis aos signos da doença" (DELEUZE, 1998, p.10). Assim, em cada campo de signos ficamos decepcionados quando não alcançamos o segredo que esperávamos. Para Deleuze (1998, p. 46), poucas são as coisas que não decepcionam à primeira vez que as vemos ou fazemos, "porque a primeira vez é a vez da inexperiência, ainda não somos capazes de distinguir o signo e o objeto: o objeto se interpõe e confunde os signos".

$\mathrm{Na}$ infância, diz Bachelard (1989, p.122) o medo trava a curiosidade. Essa relação entre medo e curiosidade que acompanha toda ação inicial sobre o mundo é reativada ou restaurada na própria observação de uma ingenuidade, isto é, revivida nas primeiras observações, naquelas que começam algo. O limiar sensível de toda ação de começar algo no mundo está paradoxalmente entre o intenso interesse de agir e o receio de agir. Nesse limiar o interesse ondula, perturba-se, volta e revela estranhas sutilezas quando as ondulações de medo e curiosidade são amplificadas pela imaginação, quando a realidade não está ali presente para moderá-las.

Acompanhar a tensão deste momento de inserção das primeiras aprendizagens no coletivo envolve considerar e acolher as dificuldades vividas, os obstáculos que cada criança enfrenta em suas tentativas e esforços para ultrapassá-los e superá-los, os equívocos necessários e os inúteis, os medos e as alegrias ante o espanto da novidade que é o desconhecido. Nesse processo experiencial do devir das condutas na convivência, 
a criança aprende a decifrá-las porque aprende a redimensionar o já emocionado - o já ritmado no corpo fabulando e ficcionando. Aprende a tomar a decisão de começar algo para tornar-se gesto no mundo.

Aqui, aprender não diz respeito a processos cumulativos do percebido, mas à metamorfose do corpo em abertura para a experiência temporal de comescar-se. Convém destacar que o processo da metamorfose é delicado, pois implica mudança radical no corpo sem a sua perda ou destruição: todo o ser transforma-se mantendo-se, conservando-se. Processo temporal, histórico, sempre inacabado pelo movimento do corpo em sua conquista de outros movimentos.

Essa dinâmica transfigurativa faz o corpo aprender a agir de outros modos porque alterou-se em suas metamorfoses. A metamorfose, em Bachelard (1997), é meio de concretizar de imediato um ato vigoroso: a conquista de outro movimento, outro tempo. Portanto, não são gestos superados, mas gestos ritmados que duram em suas descontinuidades.

Apenas por serem descontínuos podem ser re-arranjados, podem começar sempre "outra vez" e assim inaugurar outros gestos. O corpo mexe-se, desloca-se, inventa e sedimenta gestos. A recursividade temporaliza-se na repetição mesma: inventam-se, recomeçam, retomam, reinventam-se, complexificam-se em atualizações que engendram repertórios gestuais - e imagéticos - no movimento mesmo das diferenciações que vão nos diferenciando. Aqui não há simbolismo nem redução ao psicológico, é processo de individuação a partir da dinâmica entre a repetição e a diferença (DELEUZE, 1988). É o corpo antes do verbo.

Nas palavras de Bachelard (1994, p.132), "os largos ritmos marcam a vida humana": a marcam e a assinam. Essa nossa marca rítmica, esse acordo temporal que nos vincula às primeiras aprendizagens da infância, o mundo da primeira vez, Bachelard (1988, p.119) designa como acordo poético para demonstrar que "a infância permanece em nós como um princípio de vida profunda, de vida sempre relacionada à possibilidade de recomeçar. Tudo o que começa em nós na nitidez de um começo é uma loucura da vida".

A infância permanece em nós porque o acordo poético entre nossas imagens primais nos liga ao mundo quando revivificadas por nossas reservas de entusiasmos, nos fazendo confiar no mundo para tomar a iniciativa de retomá-los. A poesia permanece porque retoma descontinuidades que nossas ressonâncias-repercussões afetivas conferem coerência ou continuidade. Então, as imagens se enlaçam e se perdem, se elevam, apresentam o realismo do ficcional.

Para Rancière (2005, p.58) “o real precisa ser ficcionado para ser pensado"11 e é apenas nessa referência produtora da ficção que a experiência humana, em sua dimensão temporal profunda, não cessa de ser refigurada.

Pela imaginação alcançamos a ficção como astuto e sutil antídoto para a inevitável disjunção entre os limites de nossa realidade e nossos apetites desmedidos. Graças a ela somos mais e somos outros sem deixarmos de ser os mesmos. Podemos nos dissolver e nos multiplicarmos, vivendo muito mais vidas

"Rancière (2005, p.58-59) adverte que "essa proposição deve ser distinguida de todo discurso - positivo ou negativo - segundo o qual tudo seria 'narrativa', com alternâncias entre 'grandes' e 'pequenas' narrativas. (...) Não se trata de dizer que tudo é ficção. (...) Não se trata pois de dizer que a 'História' é feita apenas das histórias que nós nos contamos, mas simplesmente que a 'razão das histórias' e as capacidades de agir como agentes históricos andam juntas. A política e a arte, tanto quanto os saberes, constroem 'ficções', isto é, rearranjos materiais dos signos e das imagens, das relações entre o que se vê e o que se diz, entre o que se faz e o que se pode fazer". 
para além ou aquém da que temos e das que poderíamos viver se permanecêssemos confinados a um único real. É do pensamento aventurar-se - correr riscos - pelo artesanato das linguagens, nunca puro nem isolado de sua presença temporal no mundo.

Nesta perspectiva, o modo como se imagina é mais instrutivo - ou formativo - do que aquilo que se imagina. Não para "adquirir" ou "acumular conhecimentos", mas para aprendermos outros modos de plasmar ficções que permitam ultrapassar a contingência dada pelo lugar e tempo de nascimento. Como diz Pascal Quignard (apud BÁRCENA, 2004, p.13), "não conheço nada mais depreciável que um homem que não pode escapar do lugar de nascimento e desligar-se dos laços que lhe foram impostos pelo terror obediente, familiar, social, impessoal e mudo dos primeiros anos".

Aqui, talvez, a questão mais inquietante lançada pelas crianças à pedagogia: o direito a animar as coisas e emprestar-lhes uma existência poética em sua conquista linguageira de brechas entre vida real e vida fabulada. Nesse espaço de abertura à invenção de si e do mundo a criança aprende a resistir ao que é demasiado real na simultaneidade que aprende a iniciar um gesto que a expõe até o desconhecido e incerto. É nesse espaço de abertura às metamorfoses do corpo que habita o poético e seu poder de nos expor ao invisível, ao informe, ao não pensado ainda.

Recuperar para a racionalidade o poder produtivo da imaginação decifrar e engendrar sentidos que produzem efeitos no real, desde as primeiras aprendizagens na infância, é destacar a dimensão formativa dos processos de aprender a ficcionalizar o vivido para colocar-se em movimento, partir a um futuro ${ }^{12}$.

É reclamar o direito à experiência de maravilhamento - de uma alegria fascinada - diante das primeiras admirações com a plasticidade do mundo que convocam o corpo da criança a "mexer-se" e lançar-se para encená-lo enquanto estratégia de um pensamento aderido ao mundo. Antes, porém, implica uma atitude crítica corajosa cujo desafio é a nossa própria condição de professoras e pesquisadoras de crianças pequenininhas.

\section{Outra pedagogia é possível}

$A$ arte existe porque só a vida não basta. FERREIRA GULLAR

O direito à educação das crianças pequenas é um direito diferente do direito à educação escolarobrigatória. Diferente também foi a luta para alcançá-lo, nesta dimensão o direito à educação em creches tem inovado a formação docente. Até então, quem exercia essa função eram muitas vezes guardadeiras, enfermeiras, assistentes sociais e, às vezes, até pedagogas, que apenas cuidavam e tomavam conta das crianças, educando, portanto, sem os referenciais científicos (nem artísticos) da educação. Assim, se por um lado a Pedagogia não estava sendo vista como uma Psicologia aplicada, por outro lado, essas práticas pedagógicas não-escolares foram sendo construídas por profissionais (com ou sem diploma) muitas vezes já centrada na animação e na manipulação e não com a didática e a transmissão de conhecimentos.

12Bachelard (1989, p.18), sustenta que "com sua atividade viva, a imaginação desprende-nos ao mesmo tempo do passado e da realidade. Abre-se para o futuro". 
A educação infantil não está centrada na aula, no ensino, na figura da professora, no binômio ensino-aprendizagem. A educação infantil está centrada na experiência infantil, no processo, e não no produto, não no resultado. A professora de creche é uma professora de criança e não professora de disciplina escolar. Portanto, sem salas de aula, sem classes, sem alunos(as).

Nesta perspectiva nos questionamos, no que aprendemos e o que ensinamos nos cursos de pedagogia para poder trabalhar e conviver com crianças que ainda não falam, ainda não andam, ainda não lêem nem escrevem com as letras? O que aprendemos sobre as crianças de 0 a 3 anos, além do enfoque científico predominantemente psicológico que geralmente isola a mente do corpo? Como constroem as crianças, desde bem pequenas, saberes e falares entre elas? Como se dá a produção das culturas infantis nesse espaço coletivo de educação na esfera pública (complementar à esfera privada da família), com profissionais docentes que criam condições adequadas, com materiais diversos e complexos, organizando o espaço e o tempo? Na verdade, temos uma profissão que está sendo inventada: a docência na educação infantil que deve integrar a ciência, a arte e a técnica, portanto, superando o tecnicismo pedagógico e o cientificismo.

As pesquisas sobre o coletivo infantil em creches, realizadas apenas desde os anos de 1970 demonstram que as crianças aprendem mesmo quando os adultos não têm intenção de ensinar (GUNNARSON, 1994). Portanto, insistimos e defendemos que se faz necessário um currículo para a educação infantil em continuidade - creche ( 0 a 3 anos) e pré-escola (4 a 6 anos) - e também se faz necessário contaminar a educação das crianças dos anos iniciais da escola obrigatória e construir um currículo para uma pedagogia da infância centrado na criança de 0 a 10 anos levando em conta suas especificidades etárias: ampliar a formação teórica para a docência sem antagonizar a cultura lúdica e as culturas da escrita, além de profunda formação em arte, que proporcionará atenção para as diversas formas sofisticadas de organização do pensamento durante a infância, distinta da poderosa organização alcançada com a escrita e que devem estar em concomitância nas sociedades grafocêntricas.

Devemos parar de pensar em educar através de ensino e de currículos prontos. Devemos privilegiar a auto-aprendizagem das crianças e encontrar com elas os currículos e os campos de experiência ${ }^{13}$. E, tendo conosco nesta empreitada, as contribuições das famílias. Se nós adultos colaboramos discutindo, pensando e pesquisando fora de qualquer conformismo, então podemos oferecer às crianças um modelo de valor. É isso que tentamos. (...) Ver, tocar e demonstrar é algo extraordinário para uma pedagogia que, frequentemente, ao contrário, simula, oculta e se limita somente às palavras. (MALAGUZZI apud AMBECK-MADSEN, 1992, p.19) grifos nossos

Desde os anos de 1960, trabalhando, educando e observando crianças bem pequenas, o italiano Loris Malaguzzi buscou em outros campos de conhecimento novos diálogos e interpretações do mundo infantil e adulto e, assim, recuperando a dimensão estética na forma de produção de conhecimento humano, propôs a criação do atelier para a organização do trabalho pedagógico em creches e pré-escolas. Podemos

13. Eis os campos de experiência educativa das novas orientações para a escola da infância italiana de 1991: a) 0 corpo e o movimento, b) os discursos e as palavras, c) o espaço, a ordem, a medida d) as coisas, o tempo, a natureza, e) mensagens, formas e mídia, f) o eu e o outro. Para as crianças de 0-3 anos em creche os italianos Borghi e Guerra (1999) propõem: a) percepção e movimento, b) o gesto, a imagem, as palavras, c) os problemas, as tentativas, as soluções, d) a sociedade e a natureza, e) o eu e o outro (FARIA, FINCO, BARBOSA, 2015). 
dizer que esta pedagogia tem na arte seu fundamento, além da ciência que é permanentemente problematizada.

Malaguzzi atuou como professor, secretário de educação e foi um transgressor e inventor de pedagogias, em parceria com os governos comunistas e feministas que predominaram no norte da Itália nos anos 60. Era um "criancista" e revolucionou o conceito de infância como "pré-pessoa", apenas como um "vir a ser adulto". Teve na Política e na Educação o lócus privilegiado para trabalhar a favor da consciência coletiva dos direitos das crianças;

A proposta do ateliêr prevê que

a arte aprende-se fora da arte, o desenho não se aprende somente desenhando certamente há necessidade de aprendizagem de técnicas, porém se aprende tanto desenhando quanto fazendo outras coisas...e, por outro lado, a lógica se aprende também pelo desenho, projetando e construindo... A arte usa as roupas de todos os dias, não a roupa de domingo (MALAGUZZI apud RABITTI, p.149, 1999).

Desta forma, o atelier atualizou a cultura italiana da imagem gerando, não um espaço separado onde é cômodo pintar, desenhar, fazer esculturas, construir engenhocas, etc, e onde se pode sujar e bagunçar, mas gerou o trabalho conjunto da atelierista, da professora e das crianças. Nesta relação a três se potencializa o desenvolvimento integrado das cem linguagens como diria Malaguzzi. Isto é, a construção de todas as dimensões humanas e assim de todas as formas de expressão e comunicação de estar no mundo. Este processo representa um corte nos métodos da pedagogia tradicional, que devem ser revolucionados para contemplar a abrangência da infância: a observação e a documentação são inseparáveis no atelier.

O atelier supõe uma transgressão física: segundo a idéia de Rodari, seria “...um diálogo que interrompe a assim chamada normalidade educativa”. Malaguzzi já tinha comentado: há muita normalidade na escola. $\mathrm{O}$ atelier convida as crianças e os adultos a experimentar, a provocar, a procurar, a brincar com a loucura. (HOYUELOS, 1998, p. 7)

Os modernistas, já no início do século XX, diziam que as crianças são inventivas e quando expressam essa inventividade, por exemplo, nos desenhos, (re)inventam inclusive a perspectiva (GOBBI, 2004). As pesquisas recentes têm mostrado que as crianças são comunicadoras por excelência, são construtoras da história e da cultura, são capazes de múltiplas relações e não são alunas - sem luz -, mas são capazes de sofisticadas formas de organização do pensamento e de sua manifestação em diferentes formas de expressão mesmo antes de ler e escrever.

Assim, faz-se necessária uma outra formação profissional docente (formação + pesquisa= inovação), também sofisticada, e uma pedagogia para/da infância que não seja apenas sinônimo de ler e escrever, e que não faça da palavra um atalho para o conhecimento (MALAGUZZI,1988), com professores(as) capazes de trabalhar com idades misturadas, em duplas de adultos sem hierarquia, "alfabetizados" nas cem linguagens, críticos das pedagogias espontaneístas e cognitivistas, superando os binarismos.

A professora não ensina, mas, com intencionalidade educativa planeja, organiza e coloca à disposição das crianças tempos, espaços e materiais para que favoreçam provocações à imaginação e desafios ao raciocínio, dando asas à curiosidade, proporcionando espanto, descoberta, maravilhamento e todas as formas de expressão nas mais diferentes intensidades. 
A inteligência se adquire usando-a (MALAGUZZI, 1988). Assim, a organização do espaço físico também precisa ser revista para permitir o imprevisto e que uma pedagogia da escuta, uma pedagogia das relações, uma pedagogia das diferenças possa ser construída, em continuidade com os anos iniciais do ensino fundamental.

A pedagogia malaguzziana é complexa: 'se permite' interpretações subjetivas, divergentes e independentes sobre o mundo, em contraste com uma ideia de progresso linear e cumulativo. É cética em relação às certezas passadas, presentes e futuras; está preparada para libertar-se dos cânones hegemônicos da pedagogia e da psicologia. A pedagogia malaguzziana também é estética pela sua capacidade de mostrar o essencial através de novas relações, com proximidades aparentemente longínquas. Vive uma tensão transgredindo ela mesma, sem trair-se, e ao mesmo tempo [...] uma comunicação metafórica e simbólica que multiplica a nossa imagem do mundo e da infância (HOYUELOS, 2004, p.7).

Loris Malaguzzi teve como referência para este projeto, de construção das bases para uma nova cultura da infância, que inspira pedagogias da infância em vários países do mundo (GANDINI, 2012), uma 'nostalgia' de futuro, com seus amigos, parceiros e colaboradores: artistas, educadores, comunistas e feministas, portadores de uma herança trágica que foi a experiência com a $2^{\circ}$ Guerra Mundial. Assim como as crianças e o sentimento de infância explode no cinema neo realista italiano, a pedagogia da infância e toda a cultura da infância, na literatura, design, no teatro, etc... de certa forma se alimentam desta nostalgia de futuro, que torna-se projeto, no qual as crianças são sujeitos da história (SILVA, 2014).

No epicentro de sua prática política pedagógica, buscou inventar uma Pedagogia Fantástica inspirada, entre outros, em Gianni Rodari, um poeta, escritor de histórias infantis traduzidas em muitas línguas que esteve em um evento de formação em Reggio Emilia e depois dedicou a ela e suas crianças seu mais famoso e genial livro (A Gramática da Fantasia, 1973). Essa relação com Rodari foi fundamental nas bases desta pedagogia que, desde o início da sua carreira, sempre buscou da relação com a pedagogia "científica", com a pesquisa constante, com um rigor para a educação da primeira infância, objetivando o reconhecimento e a necessidade de construir uma identidade forte. Porém, percebe a importância de encontrar uma interlocução entre a razão e a fantasia, entre a ciência e a imaginação, como declara na sua poesia mais célebre, que exalta as cem linguagens das crianças (FARIA e SILVA, 2013).

A experiência histórica da pedagogia da infância italiana nos inspira refletirmos nesta emergente interface entre estética e poética, arte e ciência, alinhavando interlocuções possíveis, com saberes e sabores que fazem política na concepção de educação que está centrada na experiência para, das e com as crianças. Tendo no passado e na contemporaneidade a arte como fundamento na formação docente como oportunidade de explorar, conhecer e conhecer-se, experimentar (INFANTINO e ZUCCOLI, 2015). Educação, ciência e arte, centrada nos processos mais do que produtos, que transgrida e liberte também os anos iniciais do ensino fundamental, com um novo paradigma epistemológico para uma didática da maravilha (NIGRIS, 2014).

Possibilitando nesta perspectiva político pedagógica o convívio das diferenças, que permitirá que a criança, desde pequena, possa conhecer a origem da desigualdade e vislumbrar o movimento que aponte possibilidades de superação. Portanto, temos um(a) docente comprometido(a) com o conhecimento, 
cúmplice da invenção de saberes com as crianças, que cria instalações. Sem dar aulas atuará como se fosse um cenógrafo, um criador de ambientes para que a infância aconteça. Um performático. Como diz Walter Benjamin (1984), o professor de crianças é como um diretor de teatro: convida a criança para sentir, pensar e agir concomitantemente, sem separar a cabeça do corpo, cria as condições para que cada uma atue e se articule com o coletivo divertindo-se e comunicando-se.

Trata-se, portanto, de uma nova formação docente, que garantirá a continuidade da educação no coletivo das crianças de todas as idades. O compromisso com o conhecimento, produto da formação científica e artística na docência para a infância, favorecerá a construção de uma pedagogia capaz de formar o cidadão de pouca idade centrada em ações integradoras do ser, tais como o brincar e as manifestações artísticas, ações humanas onde sentir, pensar e fazer podem não estar dissociados, desde que a intencionalidade educativa do adulto profissional assim o desejar. Essas ações corresponderão a mais um "ensaio de humanidade" já que estamos longe de constituí-la plenamente. São uma confirmação esfuziante da possibilidade do homem (GARDNER, 2004).

Ainda nesta interlocução entre arte e pedagogia, ressaltamos uma experiência e possibilidade de uma outra pedagogia possível, brasileira e macunaímica, descolonizadora, evocada com uma citação de 1929 (o mesmo período em que Benjamin está escrevendo sobre infância) de um poeta brasileiro, Mário de Andrade, que em 1935, quando foi diretor do Departamento de Cultura da prefeitura da cidade de São Paulo, criou os parques infantis para as crianças das famílias operárias, que sem ter aulas, foram educadas na diversidade cultural brasileira, na arte e brincando.

A criança é essencialmente um ser sensível a procura de expressão (...) ela é muito mais expressivamente total que o adulto. Diante de uma dor: chora - o que é muito mais expressivo do que abstrair: "estou sofrendo". A criança utiliza-se indiferentemente de todos os meios de expressão artística, emprega a palavra, as batidas do ritmo, cantarola, desenha. Dirão que as tendências dela ainda não se afirmaram. Sei. Mas é esta mesma vagueza de tendências que permite para ela ser mais total. E aliás as tais "tendências" muitas vezes provêm da nossa inteligência exclusivamente (ANDRADE, 1993, p.29).

Com nostalgia do futuro e otimismo da vontade, apesar dos retrocessos em tempos sombrios, defendemos que temos sido historicamente muito criativos e inventado muitas formas de educar as crianças pequenas sem didatizar o lúdico e sem pedagogizar a arte. Reforçando que a construção do indivíduo como eixo central da escola, que geralmente se transforma em individualismo, pode ser superada com a construção da infância, do coletivo infantil, da diversidade que rompa com a fôrma tradicionalmente escolar (FARIA, 2007b).

Articular o sistema nacional de ensino/educação também com as práticas de educação nãoformal pode favorecer a construção de uma Pedagogia da Infância centrada na criança e principalmente nas dimensões humanas negligenciadas pela escola obrigatória: o lúdico, a imaginação e o ficcional.

Por fim, para não perdermos tudo isso, acreditamos ser necessário transbordar as poéticas do cotidiano que permeiam a pedagogia da infância na educação infantil e contaminar a escola fundamental com a didática da maravilha. A docência na creche, na pré-escola e nos anos iniciais do Ensino Fundamental podem ser aliadas nesse processo e a arte ser a grande aglutinadora de encontros poéticos, políticos e pedagógicos que garantam o direito pleno à infância e à educação. 


\section{Referências}

ABRAMOWICZ, Anete. O direito das crianças à educação infantil. Pro-posições. Campinas: v.14, n.3 (42),p.13-24, 2003.

AGAMBEN, Giorgio.Infância e história: destruição da experiência e origem da história. Belo Horizonte: Editora UFMG, 2005.

AMBECK-MADSEN, P. Attività prescolastica: Reggio Emilia, Italia: non si deve porre limite all’infanzia. Il prêmio Lego,1992. Ygdrasil,1992.

ANDRADE, MARIO. Sobre o desenho de crianças, manuscritos não publicados. IEB, USP, 1993.

ARENDT, Hannah. A condição humana. Tradução de Roberto Raposo, posfácio de Celso Lafer. 10.ed. Rio de Janeiro: Forense-Universitária, 2004.

BACHELARD, Gaston. A poética do devaneio. Tradução Antonio de Pádua Danesi. São Paulo: Martins Fontes, 1988.

BACHELARD, Gaston. A poética do espaço. Tradução Antonio de Pádua Danesi. São Paulo: Martins Fontes, 1989

BACHELARD, Gaston. Lautréamont.Traducción Angelina Martín del Campo. México, D.F.: Fondo de Cultura Económica, 1997.

BÁRCENA, Fernando. El delirio de las palabras. Ensayo para una poética del comienzo. Barcelona: Herder, 2004.

BENJAMIN, Walter. Rua de mão única. Tradução Rubens Torres Filho; José Carlos Martins Barbosa. 5. ed. São Paulo: Brasiliense, 1995.

BENJAMIN, Walter. Reflexões: a criança, o brinquedo e a educação. São Paulo: Summus, 1984.

BORGHI, Battista Quinto e GUERRA, Luigi. Manuale di didattica per l'asilo nido.Bari: Laterza,1999.

DELEUZE, Gilles. Proust et les signes. Paris: Quadrige, PUF, 1998.

DELEUZE, Gilles. Diferença e Repetição. Tradução de Luiz Orlandi, Roberto Machado. Rio de Janeiro: Graal, 1988. 
FARIA, Ana Lúcia G. de. LorisMalaguzzi e os direitos das crianças pequenas. In: OLIVEIRAFORMOSINHO, J.; KISHIMOTO, T.M.; PINAZZA, M.A. (orgs.). Pedagogia(s) da infância: dialogando com o passado, construindo o futuro. Porto Alegre: Artmed, 2007a, p. 277-292.

FARIA, Ana L. G. (org) O coletivo infantil em creches e pré-escolas: falares e saberes. São Paulo: Cortez, 2007b.

FARIA, Ana Lúcia G. e SILVA, Adriana A. Por uma nova cultura da infância: LorisMalaguzzi.Revista Educação Especial, SÃO PAULO: v. X, p. 98-111, 2013.

FARIA, Ana Lúcia G.; FINCO, Daniela; BARBOSA, Maria Carmen. (organizadoras). Campos de experiências na escola da infância contribuições italianas para inventar um currículo de educação infantil brasileiro, Campinas, SP: Edições Leitura Crítica, 2015.

FRANCASTEL, Pierre. A realidade figurativa. Tradução Mary Amazonas leite de Barros. São Paulo: Perspectiva, 1993.

GARDNER, Howard. I cento linguaggi di una riforma educativa di sucesso. Bambini inEuropa. anno 4, N. 1, p.16-17, feb. 2004.

GANDINI, Lellaet al. (Orgs.). O papel do ateliê na educação infantil: a inspiração de Reggio Emilia. Porto Alegre: Penso, 2012.

GOBBI, Marcia A. Desenhos de outrora, desenhos de agora: Mario de Andrade e seu acervo de desenhos de crianças pequenas. Tese de Doutorado. Faculdade de Educação da Unicamp, 2004.

GUNNARSON, Lars. A política de cuidado e educação na Suécia IN Rosemberg. IN ROSEMBERG, Fulvia e CAMPOS, Maria M.(orgs) Creches e pré-escolas no Hemisfério Norte. São Paulo: Cortez, 1994, p.135-188.

HOYUELOS, Alfredo Planillo. Malaguzzi e l'atelier: complessità dei possibili IN MANTOVANI, Susanna (a cura) Nostalgia del futuro. Bergamo: Junior, 1998, p.64-69.

HOYUELOS, Alfredo Planillo. Loris Malaguzzi: una bibliografia pedagógica. Bergamo: Junior, 2004.

INFANTINO, Agnese. e ZUCCOLI, Franca. A arte como ferramenta de exploração e conhecimento. Revista Eventos Pedagógicos Dossiê Educação de 0 a 3 anos em espaços de vida coletiva. v. 6, n. 3 (16. ed.), edição especial temática, p. 75-94, ago./out. 2015. 
MALAGUZZI, Loris. Intervista a Catini, Enzo. Bambini. anno IV, N.12, dicembre 1988.

MERLEAU-PONTY, Maurice. O visível e o invisível. Prefácio e posfácio de Claude Lefort. Tradução José Artur Gianotti e Armando Mora d'Oliveira. São Paulo: Perspectiva, 1999.

NIGRIS, Elisabetta, A “didática da maravilha”: um novo paradigma epistemológico. In GOBBI, Marcia A. e PINAZZA, Monica A. (Orgs.) Infância e suas linguagens. São Paulo: Cortez, 2014.

RABITTI, Giordana. À procura da dimensão perdida: uma escola de infância de Reggio Emilia. Porto Alegre: Artes Médicas Sul, 1999.

RANCIÈRE, Jacques. A partilha do sensível: estética e política. Tradução Mônica Costa Netto. São Paulo: EXO experimental org.; Ed. 34, 2005.

RICHTER, Sandra R. S. A dimensão ficcional da arte na educação da infância. Faculdade de Educação, Universidade Federal do Rio Grande do Sul, Porto Alegre, 2005. Tese de Doutoramento.

RICHTER, Sandra R. S. O ateliê na educação de crianças pequenas. Revista Pátio Educação Infantil. Porto Alegre, ano V, n. 14, julho/outubro 2007, p. 44-46.

RICOEUR, Paul. Du texte à l'action: essais d'herméneutique II. Paris: Éditions du Seuil, 1986.

RODARI, Gianni. Grammatica della Fantasia. Introduzione all'arte di inventare storie. Trieste: EinaudiRagazzi, 2013.

SILVA, Adriana Alves. A Estética da Infância no Cinema: poéticas e culturas infantis. Tese de Doutorado em Educação, Faculdade de Educação, UNICAMP, Campinas, 2014.

VALÉRY, Paul. Variedades. São Paulo: Iluminuras, 1999.

VARELA, Francisco; THOMPSON, Evan; ROSCH, Eleanor. De cuerpo presente. Barcelona: Gedisa, 1997. 